\title{
FURTHER NOTES ON THE APPARATUS CRITICUS*
}

Abstract: This article is intended to contribute to an emerging debate regarding the proper contents and shape of a digital apparatus criticus. Iargue that Keeline (2017) offers what are in fact two very different proposals for such an apparatus, one of which will likely serve our interests as a profession far more effectively than the other. Keeline treats the general contemporary tendency to disregard the critical apparatus in printed texts as a problem that must be corrected. I suggest that it is better understood as a reasonable response to the enormous intellectual expansion of the field of classical studies over the last few generations, and that it is accordingly unlikely to respond to changes in the architecture of the critical apparatus in any format.

7 om Keeline begins a recent article in this journal with the assertion, "it is a truth universally acknowledged that no one except textual critics and pedants actually reads an apparatus." This is an exaggeration rather than a "truth universally acknowledged." But like many exaggerations, it is based on a kernel of perceived commonplace wisdom, which is that modern readers often pay little attention to the critical apparatuses of Greek and Latin texts and that, as Keeline observes a few lines later, "this is unfortunate." The bulk of Keeline's paper consists of an attempt to explain why the traditional critical apparatus is ignored, and to argue that the situation might be altered by the possibilities opened up by electronic publication. Were the program he outlines adopted, he suggests, "textual criticism would undergo a renaissance," and the state of affairs the article begins by lamenting might be corrected. Keeline expressly sets his argument in the context of discussion of the eventual architecture of the Digital Latin Library. But the issues he raises are larger than this, as editorial practices generally begin to

\footnotetext{
* Thanks are due Benjamin W. Millis and the anonymous referees for Classical Journal, whose comments on an earlier draft of this piece sharpened my thinking and altered the presentation of a number of portions of my argument.

${ }^{1}$ Keeline (2017) 342.

${ }^{2}$ Keeline (2017) 361.
}

THE CLASSICAL JOURNAL 114.3 (2019) 330-344 
migrate across the electronic frontier, ${ }^{3}$ and as conversations take place regarding potential new types of critical apparatuses and the purposes an apparatus ought to serve. Paradigm shifts of this magnitude are rare in our field, and the decisions associated with this one require a clear understanding of what a critical apparatus does (or is supposed to do) and of the role that editors and the texts they create have traditionally played in the field of classical studies. This is accordingly the moment to think as clearly as we can about the investment various forms of proposed apparatus documentation will require; about how useful such documentation will be in practice; about the advantages and disadvantages that various textual practices may bring with them for the field as a whole; about what we wish to preserve, as well as what we ought to change, as we move into a potentially very different style of academic publication; and about who we really are as scholars.

\section{The Critical Apparatus: Preliminary Observations}

Keeline begins the first section of his article ${ }^{4}$ with a quotation from Martin West's well-known Textual Criticism and Editorial Technique, in which West observes:

Critical apparatuses have more than one use. The most essential one is to inform the reader which parts of the printed text depend on emendation and which parts are subject to uncertainty. But apparatuses are also what most people depend on for instruction about the character of particular manuscripts and scribes, and of manuscripts and scribes generally. ${ }^{5}$

This is an extremely compact definition and, as Keeline observes in a footnote later on, ${ }^{6}$ is cast in objectivist language that obscures a basic aspect of the structure and content of the critical apparatus, which is that it reflects the judgment of a single editor (or a single editorial voice) standing in to some extent for the scholarly tradition as a whole. The critical apparatus of West's own Aeschylus, for example, tells us not so much "which parts of the printed text depend on emendation and which parts are subject to uncertainty" as which parts of the printed text depend

\footnotetext{
${ }^{3}$ Despite Keeline (2017) 350, the technical hurdles this migration faces appear to be significant, which must be among the reasons why no fully digital edition of a classical text has yet appeared even after many years of discussion and considerable investment of resources.

${ }^{4}$ Keeline (2017) 343.

${ }^{5}$ West (1973) 86.

${ }^{6}$ Keeline (2017) 345 n. 11.
} 
on emendation or are subject to uncertainty in the judgment of Martin West, incorporating to some extent the opinions of earlier scholars. As editor of the text, West may disregard suggestions advanced by other scholars, despite the fact that they for their part must have regarded them as correct or at least as worthy of consideration. He may also call into suspicion words or passages that have never been suspected before, voicing opinions in regard to them that no one after him may endorse. This is thus a deeply subjective exercise even while it tries to deal with seemingly objective facts, and the same is true of reports of manuscript readings and conjectures. Most editors eliminate at least some manuscripts of their text ( $s c$ as copies of others, and thus of no independent value as witnesses), and very few editors report all readings in even the manuscripts they do consider (because some of them represent random, isolated errors, for example, that do not contribute to determining what the original author wrote, or because certain classes of variants can be regarded as matters of orthography rather than of sense and are thus unlikely to interest the vast majority of users). ${ }^{7}$ Nor do most editors print all previous conjectures on the text, but instead offer only what they judgerightly or wrongly — to be the best and most likely among them. ${ }^{8}$ What West might perhaps have said instead in the initial portion of his account of the function of the critical apparatus is that it represents in the first instance a catalogue of the evidence (generally confined to manuscripts and testimonia) taken into account by an individual editor in regard to the specific words or passages he or others have found problematic, along with notices of who has altered the text to make it read as it does now, sometimes accompanied by alternative proposals for correction. Some editors add brief comments (often to dismiss or praise a particular reading or proposal) or particularly relevant comparanda (especially to suggest why one alternative reading might be preferred to another). The point of all of this in any case is that the editor has a professional responsibility to make the reader aware of where the printed text diverges from the ancient testimony or the modern

\footnotetext{
${ }^{7}$ Cf. Keeline (2017) 352.

${ }^{8}$ Why Keeline (2017) 351 asserts that "many conjectures are simply impossible" is unclear. Very few conjectures are "impossible", except in the sense that if there are e.g. five conjectures on an individual passage, at least four of them (80\%) must be wrong. Most conjectures on classical texts have been made by competent Hellenists and Latinists, even if their understanding of the history of specific forms, syntax, usage and the like may differ from our own. Modern editors reject many of the conjectures offered over the years on various grounds, while often suggesting their own - which they presumably regard as valuable, no matter how others may judge them afterward. But these are subjective judgments that do not depend on any implicitly objective standard of "possibility" and "impossibility."
} 
handling of it in ways the editor judges significant, and thus to offer the reader the opportunity to reverse the process of selection or emendation, by preferring a different reading or conjecture. The provision of a critical apparatus, in other words, serves to remind the reader of the constructed and provisional character of the text as printed. The "rhetoric of the printed page," as Keeline puts it, may encourage "only a binary, a simple 'truth' vs. 'falsehood,' when in reality the decision may have been much closer." But the critical apparatus exists specifically to undermine this naive view of the situation, which is why every responsible editor furnishes one, in the expectation - or at least the hope - that readers will turn to it. All editors make mistakes, be it by misreading manuscripts or misrecording variants, or by failing to understand what a corruption or alternative reading represents, what form of a word is acceptable in a particular period or place, or what a specific passage in the original is attempting to communicate. As a consequence, no text is ever entirely secure and no edition can be truly definitive; and no one is more aware of this than editors themselves. ${ }^{10}$

\section{The "Unusable" Apparatus}

An apparatus is accordingly a statement of "facts," although like all statements of supposed facts, it is more subjective and more pointedly designed to advance a particular view of the textual tradition and to support a specific style of evaluating the evidence than an uninformed reader might initially suppose. To this extent, Keeline is correct to maintain that "the apparatus is, in effect, an argument in condensed form that justifies the editor's constitution of the text." ${ }^{11}$ Precisely at this point, however, Keeline makes a significant turn in his argument, by asserting that the traditional critical apparatus is not just "a poor medium" ${ }^{\text {"12 }}$ to do this work but actually "unusable." ${ }^{13}$ This is an extremely important assertion, because it represents Keeline's initial response to the problem with which his article begins: the critical apparatus as we know it is not used, he maintains, because it is unusable. In support of this assertion, Keeline cites as an exemplary case three critical

\footnotetext{
${ }^{9}$ Keeline (2017) 345.

${ }^{10}$ Keeline (2017) $345 \mathrm{n} .12$ seems to miss the point when he notes that editors on occasion "nobly insist that they want to enable readers to construct their own texts." This is always what the provision of a critical apparatus signals, whether the editor makes the point explicit or not. This does not mean that every reader follows the road laid out for him or her. But that is a different matter.

${ }^{11}$ Keeline (2017) 346.

${ }^{12}$ Keeline (2017) 346.

${ }^{13}$ Keeline (2017) 348.
} 
apparatuses on Tac. Ann. 12.50.2, where the manuscript reads in tempore bellaturos but editors generally print in tempore rebellaturos:

Fisher's OCT: rebellaturos Rhenanus: bellaturos $\mathrm{M}$

Koestermann's Teubner: bellaturos, em. Rhen.

Heubner's Teubner: rebellaturos al. Leid(re adds. lin., cf.rebellatores

Stuttg') (Rhen.)

Keeline objects that "Rhen(anus)" is insufficiently clear (for how could readers know that the reference is specifically to the 1544 edition of the Annales by Beatus Rhenanus?); ${ }^{14}$ adds that no argument is supplied to justify the emendation (e.g. that $r e$ - has been omitted by haplography after tempore); and lists a number of other considerations that he suggests must be taken into account by any editor or engaged reader determined to understand fully the choice confronted here-e.g. the possibility that the passage in Tacitus is modeled on Sallust, Frontinus or Cato, the pattern of distribution of rebello in ancient authors generally, the exact lexical range of bello and rebello and "what the probability is of corruption" (sic). An apparatus that fails to meet these demands, Keeline suggests, is "unusable even for the most advanced readership." ${ }^{\prime 15}$ The question is whether Keeline's analysis of the situation is correct, and determining that requires first a closer consideration of the various apparatuses on Tac. Ann. 12.50.2. The notes of Fisher and Koestermann are in fact exceedingly clear, even if organized in different fashions: the paradosis bellaturos has been emended to rebellaturos (which the editor has printed) by someone variously referred to as "Rhenanus" or "Rhen." Despite Keeline, one need not know who Rhen(anus) is or what period he belongs to in order to take the point. Nor is the question of whether the emendation appeared in Rhenanus' 1533 or 1544 edition of the text significant for the issue at hand, which is that rebellaturos is an emendation the reader may allow to revert to bellaturos, should he or she choose to do so. Further information regarding the manuscripts and editors in question requires reference to the lists of sigla and the prefaces of these editions. But there are no secrets here and very little obscurity — provided one is willing to undertake the pre-digital equivalent of one or two clicks of the mouse by turning a few printed pages.

\footnotetext{
${ }^{14}$ Thus Keeline (2017) 347 n. 14, nominally supplementing and correcting the information in these notes. In fact (and despite Keeline), rebellaturosis found already in Rhenanus' 1533 edition of the text.

${ }^{15}$ Keeline (2017) 348.
} 
The note in Heubner's Teubner is more complex, because more full of detailed information: <re $>$ bellaturos (thus Heubner's text) is not to be attributed simply to Rhen(anus), but is also and seemingly independently a superlinear correction in a late $15^{\text {th }}$-/early $16^{\text {th }}$-century Leiden manuscript, ${ }^{16}$ while a corrector's hand in a copy of the editio princeps found in Stuttgart $\left(\right.$ Stutt. $\left.^{2}\right)$ has rebellatores, which represents the same editorial impulse less successfully implemented. That the manuscript has only bellaturos need not be said, because this is apparent from the use of angle brackets in the text. All this information too is immediately available to anyone with a basic competence at reading a critical text and a willingness to consult the preface to Heubner's first volume. ${ }^{17}$

Keeline's three examples of a critical apparatus thus admirably perform their traditional scholarly function as e.g. West defines it. Put another way, Keeline's standard of "usability" appears to be a different—and strikingly non-traditionalone, which depends on an unexpected use of the term "argument" that begins with the claim that "the apparatus is, in effect, an argument in condensed form that justifies the editor's constitution of the text." ${ }^{\prime 18}$ This is correct, in the sense that (as noted earlier) all assertions of "fact," including those made in critical apparatuses, are "arguments." But neither West nor anyone else has ever maintained that an apparatus ought to contain the sort of extended discussion Keeline refers to as an "argument."19 Instead, what Keeline describes here is the typical content of an existing but separate genre, the commentary, which (assuming that one has been produced on the text in question) routinely supplies the sort of information Keeline rightly observes is absent from a standard printed critical apparatus.

Keeline's "usability" thus has little to do with what has traditionally been regarded as the appropriate function of the printed critical apparatus, nor does he identify any significant failings in the structure or presentation of the traditional apparatus per se. Instead, Keeline seems to be arguing that a classical text can be read in an appropriately rigorous and effective manner only when it is accompanied by both a full critical apparatus of the traditional sort and a textual commentary on a scale normally associated e.g. with a particularly expansive offering in the Cambridge Orange series; anything less is "unusable." This is in itself a problematic claim, in that the implication is that very little serious philological work can be done today, since relatively few primary texts are

\footnotetext{
${ }^{16}$ Identified by Wellesley (1989) in his East German Teubner as Leiden BPL 16 B.

${ }^{17}$ Heubner (1983) VIII-XI.

${ }^{18}$ Keeline (2017) 346.

${ }^{19}$ Keeline (2017) 348.
} 
accompanied by textual commentaries of such depth and scale. More significant for our purposes, Keeline goes on to argue that a differently designed critical apparatus willbe used, the projected happy result of the proposed changes being a general reinvigoration of textual studies as a discipline. This claim goes to the heart of the debate about the structure of digital texts. If the possibility stands before us of imagining the architecture of a new electronic apparatus, which can presumably be anything we wish, what information ought it to contain? And what are the likely effects of various proposals for its content on the readers for whom such texts are intended? These are issues that we as a profession cannot afford to get wrong, and this facet of Keeline's views on the subject accordingly deserves particularly close scrutiny.

\section{Toward a Digital Critical Apparatus: Keeline's Proposal(s)}

As noted above, Keeline's critique of the traditional critical apparatus has problematic aspects, in that it asks the apparatus to do work for which it was never intended and which it therefore cannot really be faulted for failing to achieve. The broad non-technical outlines of a potential digital "critical apparatus-plus" alternative to the current post-Gutenberg arrangement that might satisfy Keeline's concerns nonetheless seem relatively easy to sketch out: a multi-layered electronic document, the first-level content of which would record variant readings and conjectures in a manner not necessarily much different from a traditional bottomof-the-page print apparatus, but linked to explanatory and exegetical material of a sort that in print-format would be found in free-standing commentaries and the like. How this additional material would be generated is unclear, if it is not simply to be mined from existing print editions - in which case what is in question is mostly a shift in presentation format, with pre-digital documents converted into digital form, affecting questions of access but arguably not much else. Keeline himself appears to imagine that much of this additional content will be generated fresh, maintaining that "editors are already thinking through all of these issues every time they are confronted with such a problem, and the act of recording these thoughts would not entail significantly more work." ${ }^{20}$ But the case at hand (bellaturos or rebellaturos at Tac. Ann. 12.50.2) does not support the final portion of this characterization, for this is a simple correction (hence seemingly arrived at independently by a whole series of $15^{\text {th }}-/ 16^{\text {th }}$-century editors) and there is little reason to believe that every editor who chooses to adopt it will attempt e.g. to

${ }^{20}$ Keeline (2017) 348. 
document exhaustively the entire history of the use of bello and rebello before deciding what to print. Nor is the claim credible that producing commentary of the depth, scale and level of philological precision Keeline imagines "would not entail significantly more work" than producing the text itself-the amount of effort would in fact be exponentially larger - and even if the claim were true, relatively few contemporary classicists are engaged in producing either full-scale critical editions or in-depth commentaries on them. This is nonetheless all fairly clear and arguably achievable, provided that there are enough old commentaries to convert into digital form and that additional material can be generated to fill the inevitable gaps. The idea has the additional virtue of responding directly to Keeline's earlier analysis of the problem with the use of the traditional apparatus criticus and attempting to correct it.

What Keeline explicitly proposes in the second half of his article, ${ }^{21}$ however, is something entirely different, a massive electronically tagged collection of the details of every variant reading in every manuscript of the text in question, supplemented by comments regarding the exact type of error in question and a ranking on a scale of $0-5$ as to how likely the reading is to be correct, combined with a similarly exhaustive list of all proposed conjectures complete with information as to "the proposer, date, country of origin and so forth," ${ }^{, 22}$ another set of $0-5$ rankings, and a list of which previous editors accepted the conjecture into their text. Perhaps the most striking aspect of this scheme is that it fails to address the problem of "usability" as Keeline defined it earlier in his attempt to explain why modern readers of Greek and Latin texts tend not to consult the apparatus criticus. In a second unexpected argumentative move, Keeline nonetheless insists that "a sensibly designed digital apparatus" - by which he means a digital apparatus along the lines of the one just described - "will actually be used rather than sit inert and ignored at the foot of the page" and will "transform passive readers into active users." ${ }^{23}$ This is the crucial issue as Keeline has defined it—how can readers be made to look at and engage with the bottom of the printed page in a standard classical text or its digital equivalent? - and the point accordingly requires some argument. Keeline himself acknowledges this later on. But rather than offering a substantial case for the advantages inherent in his second style of proposed new critical apparatus, he merely insists that "if you build it they will come" and then goes on to maintain that "education of potential users should be a vitally important

\footnotetext{
${ }^{21}$ Keeline (2017) 350-3.

${ }^{22}$ Keeline (2017) 351.

${ }^{23}$ Keeline (2017) 350.
} 
part of any such digital initiative."24 The first point is not an argument but an example of magical thinking, while the second point actually amounts to conceding that the new digital apparatus will not do what Keeline claims it will, for surely users might be educated to use a traditional apparatus criticus as well, if they expressed any interest in doing so, which Keeline seems to acknowledge they generally do not. But these are not matters in which gracious evasions suffice. What is under discussion is a tectonic shift in the structure of the texts we use as basic research tools and the enormous investment of time and resources that will likely be required to make that shift possible. The question is thus whether Keeline's second style of apparatus will in fact be useful and - a different and not necessarily closely connected question, despite Keeline's attempt to make it sowhether it will be used.

Two concerns immediately present themselves. First, Keeline's second form of digital apparatus is imagined as containing potentially hundreds of individual datapoints for every word or phrase treated. ${ }^{25}$ Very few of these, however, will be of any significance for the constitution of the text, and some will be of no use whatsoever. As noted earlier, most manuscript variants are unique errors of no significance for establishing what the original author wrote. Editors note them for stemmatic purposes when they carry out their collations, but they do not record them in the critical apparatus, because such readings do not bring us any closer to what e.g. Tacitus wrote. Indeed, among an editor's most basic jobs is to sort such information out, so as to save other readers from having to do this themselves. Nor is it easy to see objective value in Keeline's proposed 0-5 rankings (in whose judgment?), on the one hand, or in the provision of information in connection with each suggested emendation regarding "proposer, date, country of origin and so forth" (which represents doxography and may thus have some sociological interest, but is not of any particular philological importance), on the other. If utility is to be a standard for the construction of a critical apparatus - as we all presumably agree it should, whatever we take the form ideally to containtherefore, inclusion of most of this material would represent a substantial practical step backward. After all, if readers tend to ignore and be baffled by the compact, easily decoded and immediately accessible traditional critical apparatus at the foot of the printed page, despite editors' best efforts over the years to engage them with it, why should we believe that they will pay more attention to a far more sprawling

\footnotetext{
${ }^{24}$ Keeline (2017) 360.

${ }^{25}$ Heubner (1983) VI-VIII lists 33 manuscripts, in addition to M, for example, to be taken into account for the Annales.
} 
and diffuse — and initially invisible — digital apparatus? Unless a clear, concrete and convincing answer can be offered to this question, this is not a direction that deserves to be considered for the architecture of the proposed new digital apparatus.

Second is the matter of input. In his discussion of his second style of electronic critical apparatus, Keeline is quite realistic at one point, noting that "the editorial process is laborious and time-consuming enough as it is. No one editor would be able — or would want - to do all possible encoding for a moderately complex text of any length in a single lifetime. ${ }^{26}$ As a potential alternative to imposing all this work on the individual editor, Keeline suggests adoption of "a more collaborative approach to editing: other scholars, graduate students and even undergraduates could provide additional tagging. ${ }^{27}$ Practically speaking, this too is neither feasible nor likely to be productive in scholarly terms. No responsible editor will publish e.g. lists of undergraduate manuscript collations under his or her own name without having checked them first, which removes most of the supposed advantages of such teamwork. Nor will any serious scholar rely on anonymous annotations as a basis for independent work on the text or manuscript in question, rather than doing all the work again.

To put all this a different way, the fundamental question for this and similar proposals for digital editorial work is cui bono? and at what cost? One enormous advantage of the traditional critical apparatus and of the editorial process that produces it is that editors sort out enormous amounts of philological dross and offer their readers only what they judge to be important. This does not mean that editors are infallible, which is why we have multiple editions of texts, all of them slightly different in what they read and what they report. But if the vast majority of the information about individual manuscripts that Keeline in his second proposal imagines being recorded in digital form is trivial (as it clearly is), whose interests will be served by recording it, who will wish to wade through it after it is recorded, and who will pay (in time or money) for all this tagging and posting? Perhaps this portion of Keeline's argument represents an attempt to take account of West's second mission for the traditional apparatus criticus, which is to provide "instruction about the character of particular manuscripts and scribes, and of manuscripts and scribes generally." The price that will be paid for trying to fulfil this desideratum systematically and completely, however, will be tens or hundreds

${ }^{26}$ Keeline (2017) 352.

${ }^{27}$ Keeline (2017) 352. 
of thousands of hours of sub-philological labor, the end result of which will be work that will need to be redone in any case, should someone decide to undertake detailed study of a certain aspect of a particular manuscript or set of manuscripts. This is not a reasonable investment of our time as scholars or of the time of our students, nor of the economic and political resources of the field, if only because (as noted below) we have a great deal of other work to do.

\section{Larger Implications: Text, Editor and Reader}

I turn now to some larger issues, and ultimately to the problem (or supposed problem) with which Keeline begins his article, the neglect of the traditional printed critical apparatus. As Keeline imagines it, the malleable nature of electronic texts raises the possibility of every reader producing e.g. his or her own Tacitus, beginning with some standard edition but personalizing it as wanted, and then defending the new creation "whether in the process of peer review or in the course of lively debate in the classroom."28 Quot lectores, tot Taciti (etc.). Were this change to take place, Keeline concludes, "virtually all scholarship would necessarily have a textual dimension, and textual criticism would undergo a renaissance. ${ }^{29}$ At least two significant concerns can be raised in regard to this nominally idyllic scenario.

The first touches on the matter of expertise and its implications. Keeline notes that a potential objection to his view of things might be "that readers are unqualified to make their own decisions about texts ... some will see the editor as gate-keeper, but I submit that editors should rather see their editions as gateways." 30 This judgment is phrased in a peculiar fashion, as if editors were vigorously claiming the role of gate-keepers and Keeline were offering the novel suggestion that they ought to regard their editions as gateways into the text. In fact, editors have always regarded their editions as gateways, which is why they provide a critical apparatus, to allow for further discussion of what ought to be read. Those who regard editors as gate-keepers are instead much more likely to be average readers who doubt their own qualifications to make text-critical judgments. This is not an altogether foolish attitude, and if taken seriously and treated as responsible rather than reckless behavior, it represents at least part of the explanation for the general modern neglect of the critical apparatus in the printed versions of our texts.

\footnotetext{
${ }^{28}$ Keeline (2017) 361.

${ }^{29}$ Keeline (2017) 361.

${ }^{30}$ Keeline (2017) 360.
} 
We live in an age of highly specialized knowledge, and even within the relatively tiny discipline of classical studies, traditional philology is today, for better or for worse, a minor sub-field. That many readers of ancient Greek or Latin texts prefer to keep their distance from the critical apparatus, or at least feel no interest in creating their own personal version of every author they read, is thus not only understandable but arguably to some extent wise. In such situations, many readers opt to defer to an expert, the dirty and unsettling secret - not actually a secret at all, but generally left unspoken - being that editors also make mistakes, or take on texts they ought not to, or are on occasion simply the wrong person for the job. But the same is true of barbers, accountants and auto mechanics, and given the odds, most of us still prefer to trust such nominal experts rather than do the associated jobs ourselves. To put all this another way, what Keeline imagines as an ideal new world, in which "virtually all scholarship would necessarily have a textual dimension, ${ }^{31}$ is potentially a dystopia in which those who do not wish to spend their working time on textual criticism are nonetheless required to do so, and in which no text can be consulted or quoted without fully pursuing all the philological issues it raises. This would indeed mean that "textual criticism would undergo a renaissance." But it would also mean that virtually all other work in the field would grind to a halt, if referring to e.g. Tac. Ann. 12.50.2 meant discovering answers to the long string of questions Keeline asserts must be understood before deciding whether to read bellaturos or rebellaturos there, and then working one's way in a similarly slow, painful and inefficient fashion through every other problem (including every variant in every manuscript) in every other text one attempted to read or cite. Keeline's "textual critics and pedants" ${ }^{\text {" } 2}$ might flourish and be happy in such a world. Most of us would not. And to be once again very clear: the costs involved in carrying out this project will be enormous, and we as a profession must decide whether we are willing to pay them or whether we prefer to make our investments elsewhere.

But there is yet another and more positive reason for the existence of standard texts and for generally deferring to their authority. If you and I have private, personal versions of Sophocles, Plato or Ovid, as we might have had in the $15^{\text {th }}$ century, and as Keeline imagines we will in the future, we are likely to have great difficulty talking about anything other than what to read where. And the more effort we have invested in individual "improvements" of our personal texts, the

\footnotetext{
${ }^{31}$ Keeline (2017) 361.
}

${ }^{32}$ Keeline (2017) 342. 
more such disputes we will have and the more difficult other conversations will become. Despite Keeline's rhetoric about the "fixed and immutable"33 character of the printed page, the option of altering what one finds e.g. in a standard OCT or Teubner text of a Greek or Latin author has always been available and has nothing to do with the digital revolution; if I dislike a reading adopted by an individual editor, I can strike it out with a pencil and substitute my own. Afterward, if anyone wants to discuss the matter, in the classroom or elsewhere, we can do so, and I can publish a note advocating for my choice of manuscript reading or emendation, if I and others believe it merits such treatment. This is an admirable style of reading, and there is a price to be paid for neglecting it. As a direct consequence, we will always need textual scholars and editors, if only to do this work for us where and when we decline to do it ourselves. Indeed, a case could easily be made that we need more such scholarship than the profession seems at the moment inclined to support. But we as students of the ancient world have other work to do as well, and limited resources with which to accomplish it, and even dedicated philologists will admit that not all of the most exciting work in classical studies over the last two generations has been strictly philological in nature.

\section{Some Final Observations}

Keeline's proposal for a new electronic critical apparatus thus has relatively little to do with the critical apparatus itself and is in any case two separate and in many ways contradictory proposals. Both might conceivably be rolled together into a single sprawling architecture for the new electronic apparatus. But one proposal is far less expensive than the other and much more likely to serve the needs of the average professional user. For good or for bad, neither is likely to solve the problem (or alleged problem) with which Keeline's article begins, but for very different reasons. The first proposal is expert-based and takes substantial account of the traditional role of the editor to shape and guide the reading of a classical text (or indeed of any text). An editor's job, on this view of things, is to do the vast majority of our textual work for us: to collate and group the manuscripts and examine and assess the modern critical history of the text; to eliminate manuscript features, readings and conjectures that are, in the editor's judgement, irrelevant, meaningless or unhelpful; and to choose what to read at every disputed point in the text, while simultaneously providing a clear and careful critical apparatus that makes it possible for sufficiently engaged and careful users to alter these decisions

\footnotetext{
${ }^{33}$ Keeline (2017) 345.
} 
and accept (or invent) different readings, should they wish to do. This is designed to be an open process, with readers empowered to engage in textual issues when they feel inclined to do so. But this approach to the text simultaneously depends on the notion that, to the extent that the work of manuscript collation, analysis of stemmatic relationships, and selection among variants and conjectures has been done in a responsible and thoughtful manner, it does not need to be repeated, at least not by every reader on a constant word-by-word basis. The same is true of the expert commentary that ideally accompanies such a primary text; the reason we want such work available is that it lays out what we are at least generally willing to assume represents a solid basic foundation for our own further attempts to discover what the text is saying and why. This approach saves us enormous amounts of time as individuals and as a profession, and allows us to engage in other forms of inquiry, while also providing a stable basis for discussions that are not purely philological in nature. It is also relatively easy to imagine an electronic apparatus of this sort, perhaps accompanied in some cases by limited textual notes along the lines of e.g. Lloyd-Jones and Wilson (1990), being produced at an affordable cost and being used - at least to the extent that a critical apparatus is ever used today. The final point also emerges as an alternative and arguably more generous answer to the question with which Keeline begins, as to why most contemporary classicists do not engage on a constant basis with the critical apparatus at the bottom of the printed page. The fact appears to be that most of us do not want to do so, but also that we feel secure in the belief that the primary texts we have today are largely "good enough" for our purposes. The disadvantage of this approach, as "textual critics and pedants" are fond of pointing out, is that it makes us prey to the errors and idiosyncrasies of individual editors, a tendency that can be only partially counterbalanced by the accumulation of more-still always fundamentally "expert-based" - secondary scholarship, and by the promise that the reader has the resources available to redo the editor's work at any point, should he or she choose to do so.

The second approach is essentially crowd-based and anti-hierarchical, in that it attempts to substitute large numbers of non-expert readers and their judgments for the work of a single authoritative editor. This approach potentially offers far more raw data than the first, in that in its ideal form at least it makes it possible to see what reading stands in every manuscript and edition of every individual text, and to be told how these readings have come to us, how they might be corrected or explained, and the like. But this approach is also enormously less efficient than the first, both because of the extraordinary amount of effort that would be required 
to produce an apparatus dedicated to documenting and evaluating all the various features of the textual tradition that individual editors routinely ignore or eliminate as insignificant, and because it implicitly demands that every individual user sort, consider and assess the reliability of all this information before deciding what to read at any point in the text, since otherwise the process of collecting the data has been pointless. The second approach also makes it far more difficult to go about our work as a community of students of the ancient world, in that to the extent it proves successful, we will no longer be working from common texts.

Keeline asserts that a new digital apparatus of his second sort will cause the discipline of textual criticism to flourish once again, although (as noted above) he offers no explanation of why that might be so. One might respond that we have already run this experiment once, with the traditional printed critical apparatus, and that it has not been a success, at least from one traditional perspective. Perhaps the real question, however, is whether we as classicists wish to return to being in the first instance textual critics and philologists. For good or for bad, the consensus answer at this point appears to be "No." Those who wish to invest enormous amounts of the profession's personal and economic resources in a new style of electronic apparatus built around a contrary view of the matter accordingly have an obligation to show both that the information they propose collecting will be of significant help in determining e.g. what Tacitus wrote at Ann. 12.50.2, and that there is a genuine demand for the resources they propose to offer.

S. DOUGLAS OLSON

Bilkent Universityand University of Minnesota, sdouglasolson@gmail.com

\section{WORKS CITED}

Heubner, Henricus, ed. 1983. P. Cornelii Taciti libri qui supersunt. Stuttgart.

Keeline, Tom. 2017. "The Apparatus Criticus in the Digital Age." CJ112: 342-63.

Lloyd-Jones, Hugh and Nigel Wilson. 1990. Sophoclea: Studies on the Text of Sophocles. Oxford.

West, Martin L. 1973. Textual Criticism and Editorial Technique. Stuttgart. 
Copyright of Classical Journal is the property of Classical Association of the Middle West \& South Inc. and its content may not be copied or emailed to multiple sites or posted to a listserv without the copyright holder's express written permission. However, users may print, download, or email articles for individual use. 